\title{
Electronic Elements Governing the Binding of Small Molecules to a [Fe]-Hydrogenase Mimic
}

\author{
Matthew D. Wodrich ${ }^{[a]}$ and Xile $\mathrm{Hu}^{*[\mathrm{a}]}$
}

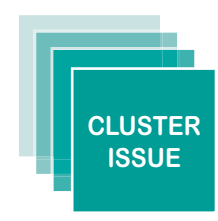

Keywords: Biomimetic chemistry / Enzyme models / Hydrogenase / Density functional calculations / Ligand effects / Iron

[Fe]-hydrogenase, one of three types of hydrogenases, activates molecular hydrogen. Here, using DFT computations, we examine the electronic elements governing the binding of small ligands to a recently synthesized [Fe]-hydrogenase biomimic. Computed reaction free energies indicate that anionic species, such as $\mathrm{CN}^{-}$and $\mathrm{H}^{-}$, and $\pi$ acceptors, such as $\mathrm{CO}$, bind favourably with the Fe centre. Ligands such as $\mathrm{H}_{2} \mathrm{O}, \mathrm{CH}_{3} \mathrm{CN}$, and $\mathrm{H}_{2}$, however, do not bind iron. Protonation of an adjacent thiolate ligand on the mimic significantly increases the energies of ligand binding. Additional computational analysis reveals that the degree of electron donation from the ligand to the mimic correlates strongly with overall binding ability. The results give insights into the electronic elements of iron-small-molecule interaction in these model complexes.

\section{Introduction}

The chemistry and biology of enzymes that use or produce hydrogen are currently subjects of a great deal of interest because of their potential use within the context of energy supply and utilization. [Fe]-hydrogenase catalyzes the reversible reduction of methenyltetrahydromethanopterin $\left(\mathrm{MPT}^{+}\right.$) with $\mathrm{H}_{2}$ to methylenetetrahydromethanopterin (HMPT) and $\mathrm{H}^{+}$(Scheme 1). The enzyme has thus received the formal name $\mathrm{H}_{2}$-forming methylenetetrahydromethopterin dehydrogenase, abbreviated as Hmd. During the catalyzed reaction a hydride ion, arising from heterolytic splitting of $\mathrm{H}_{2}$, is stereospecifically transferred to the pro- $\mathrm{R}$ face of $\mathrm{MPT}^{+}$to form HMPT, ${ }^{[1]}$ while the proton remains behind. This transformation represents an intermediate step in the reduction of $\mathrm{CO}_{2}$ to methane by methanogens grown under conditions of nickel limitation. ${ }^{[2]}$

The active site of [Fe]-hydrogenase has recently been elucidated through crystallographic and spectroscopic studies as being either five- (square pyramidal) or six-coordinate (octahedral): the central iron atom is coordinated to a cysteine sulfur atom, two cis-CO ligands, a bidentate pyridine cofactor, and possibly, a solvent molecule (Figure 1). ${ }^{[1,3]}$ Despite this uncertainty, current consensus leans toward an active site that is five-coordinate square pyramidal. ${ }^{[3 e, 3 \mathrm{~g}]}$

[a] Laboratory of Inorganic Synthesis and Catalysis, Institute of Chemical Sciences and Engineering, Ecole Polytechnique Fédérale de Lausanne (EPFL),

1015 Lausanne, Switzerland

Fax: +41-21-6939305

E-mail: xile.hu@epfl.ch

Homepage: http://lsci.epfl.ch

Supporting information for this article is available on the WWW under http://dx.doi.org/10.1002/ejic.201300081.

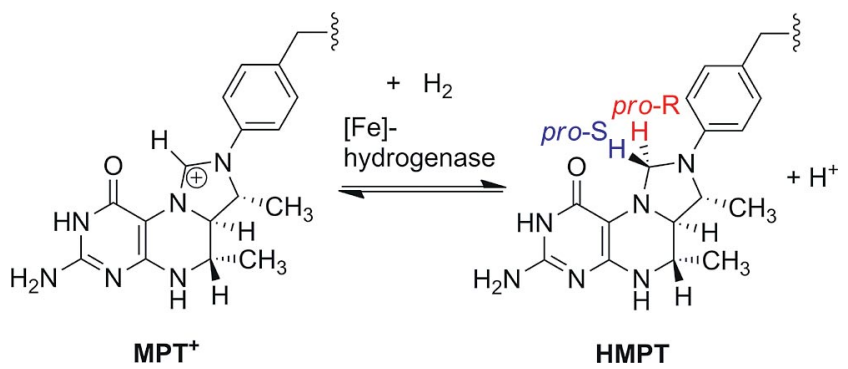

Scheme 1. Reaction of methenyltetrahydromethanopterin $\left(\mathrm{MPT}^{+}\right)$ and $\mathrm{H}_{2}$ to methylenetetrahydromethanopterin (HMPT) and $\mathrm{H}^{+}$, catalyzed by [Fe]-hydrogenase. The stereospecific addition of the hydride ion occurs to the pro- $\mathrm{R}$ face, indicated in red.
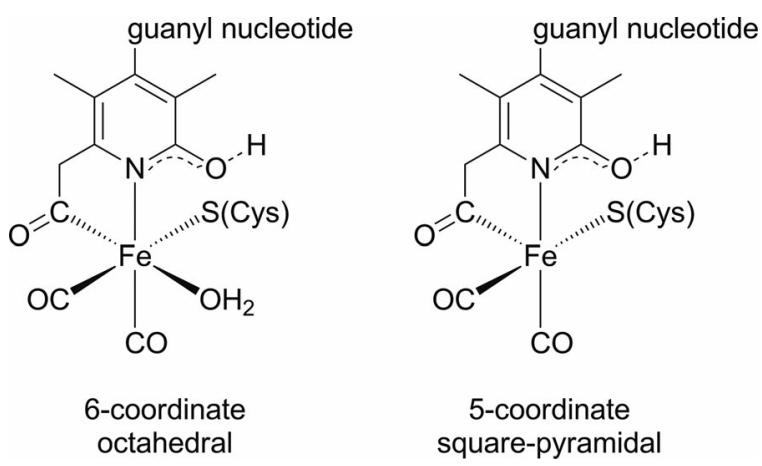

Figure 1. Two models for the proposed active site of [Fe]-hydrogenase.

In recent years the potential uses for molecular hydrogen, one of the reactants used by [Fe]-hydrogenase, have motivated the production of numerous small-molecule 
mimics. ${ }^{[3 \mathrm{~h}, 4]} \mathrm{Hu}$ and co-workers ${ }^{[5]}$ recently provided the first five-coordinate and square-pyramidal $\mathrm{Fe}^{\mathrm{II}}$ model complex that closely resembles the proposed active site of the enzyme (complex 1; Figure 2). This five-coordinate species reacted quickly with $\mathrm{CO}$ to form a mimic of the $\mathrm{CO}$-inhibited [Fe]-hydrogenase, but reactions with other ligands $\left(\mathrm{H}_{2} \mathrm{O}\right.$, $\mathrm{CH}_{3} \mathrm{CN}$, pyridine, $\mathrm{Et}_{3} \mathrm{~N}, \mathrm{O}_{2}$ ) yielded no isolable product. The reluctance of the five-coordinate complex to bind donor ligands such as $\mathrm{H}_{2} \mathrm{O}$ and pyridine is unexpected, considering the prevalence of six-coordinate iron(II) complexes. These surprising experimental findings prompted us to use computational techniques to explore the ability of 1 (Figure 2) to bind various small molecule ligands and to further uncover stereoelectronic factors influencing the reaction free energies of ligand binding.
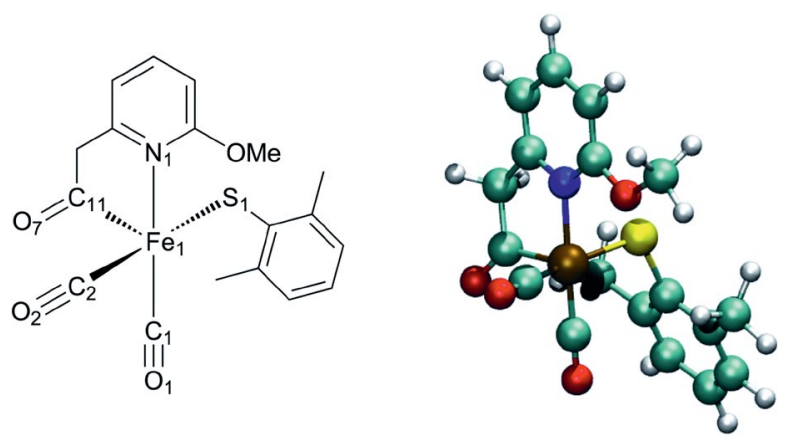

Figure 2. Schematic (left) and 3-dimensional representation (right) of the [Fe]-hydrogenase mimic complex $\mathbf{1}$.

Several previous computational studies have aimed to complement experimental work by providing greater understanding of the mechanistic and spectroscopic properties of $[\mathrm{Fe}]$-hydrogenase and related bimetallic hydrogenases. Nakatani et al. ${ }^{[6]}$ examined the $\mathrm{CO}$ stretching frequencies of several model compounds thought to represent the [Fe]hydrogenase active site, concluding that the following constituents must be present: a low-spin $\mathrm{Fe}^{\mathrm{II}}$ species, two $\mathrm{CO}$ ligands, a cysteine, and a combination of water and acylpyridinol. Dey ${ }^{[7]}$ examined CO stretching frequencies associated with a model [Fe]-hydrogenase active site to which one of several small ligands was attached (e.g. $\mathrm{H}_{2} \mathrm{O}, \mathrm{CO}, \mathrm{CN}^{-}$, $\mathrm{H}^{-}, \mathrm{O}_{2}, \mathrm{H}_{2}$ ). Assessments of the respective ligand binding energies and of variations in $\mathrm{CO}$ stretching frequencies indicated preferential binding of anionic ligands, which dissipate their electron density through the $\mathrm{Fe}$ ion and into the unoccupied orbitals of the surrounding $\mathrm{CO}$, acyl, and pyridinol ligands of the active site. Similar computational studies of $\mathrm{CO}$ and $\mathrm{CN}$ frequencies, by Reiher ${ }^{[8]}$ and by Darensbourg and Hall, ${ }^{[9]}$ have proposed details regarding the structures of reaction intermediates of [FeFe]-hydrogenase. In addition, mechanisms involving hydrogen activation have been studied in silico by Yang and Hall ${ }^{[10]}$ for [Fe]-hydrogenase. Recently, Reiher and co-workers deduced relationships between $[\mathrm{Fe}]$-hydrogenase and $[\mathrm{FeFe}]$-hydrogenase by swapping elements of the first ligand spheres of the two active sites and observing the resulting consequences in terms of small-ligand binding energies. ${ }^{[11]}$ This swap re- sulted in only modest changes to the ability of the active site to bind $\mathrm{H}_{2} \mathrm{O}$ and $\mathrm{H}_{2}$. This finding is interesting for the design of artificial hydrogenase biomimics, since it shows that certain elements of the coordination sphere around the iron atom may be replaced with little or no penalty for the binding ability of small molecules.

While qualitative observations of ligand binding in both the native enzyme and its associated biomimics provide important information regarding chemical behaviour, quantitative assessments impart additional knowledge regarding the efficiency of enzyme mimics produced in the laboratory. Examination of specific factors that influence ligand binding may ultimately improve the functionality of newly synthesized biomimics. While earlier computational studies sought to understand the behaviour of the active site in its native state, the purpose of this contribution is to establish a comprehensive picture of the electronic elements governing the interactions between the Fe complex and various ligands for a recently synthesized [Fe]-hydrogenase biomimic, complex 1 (Figure 2).

\section{Computational Details}

Electronic structure computations employed the M06 $6^{[12]}$ density functional, an alternative to the more popular M06$2 \mathrm{X}$ that better handles systems containing metal atoms. Like M06-2X, the M06 functional has been shown to describe both energies and geometric properties with greater accuracy than density functionals developed earlier. ${ }^{[12 a]}$ All geometries were optimized at the M06/pVDZ ${ }^{[13]}$ level using the "Ultrafine" grid in Gaussian09. ${ }^{[14]}$ Refined M06 energy estimates were then obtained from single-point computations with a larger triple- $\zeta$ quality basis set (def2-TZVPP). Frequency computations on the M06/pVDZ geometries provided unscaled free-energy corrections and ensured structures were minima (zero imaginary frequencies) on the potential energy surface. To fully probe the critical role played by dispersion interactions in ligand-binding free energies, single-point energies were also computed using a density-dependent dispersion correction combined with the B3LYP functional, ${ }^{[15]}$ B3LYP-dDsC, ${ }^{[16]}$ coupled with the TZP basis set, as implemented in ADF. ${ }^{[17,18]}$ The $\mathrm{dDsC}$ scheme has previously been successfully applied to diverse chemical problems: ${ }^{[19]}$ in particular, the density dependence of both the dispersion coefficient and the damping function is valuable in descriptions of charged species ${ }^{[20]}$ and transition metals. ${ }^{[21]}$ Energies of the solutes in THF were computed using two different models: the polarizable continuum model (PCM) of Tomasi and co-workers ${ }^{[22]}$ and the conductor-like screening model for realistic solvents (COSMO-RS) of Klamt. ${ }^{[23]}$ Other computations that dissected various donor/acceptor roles in $\mathrm{Fe}$ complex/ligand interactions (BLW-EDA, ${ }^{[24]}$ also called ALMO-CTA ${ }^{[25]}$ ) used the def2-SVP basis set ${ }^{[13]}$ and the M06 density functional as implemented in Q-Chem. ${ }^{[26]}$ 


\section{Results and Discussion}

\section{Comparison of Computational and Experimental Models}

To establish the validity of the computational results presented here, agreement between computed and experimentally determined geometric data for $\mathbf{1}$ was first examined. Table 1 shows that selected computed bond lengths and angles all agree reasonably well with the experimentally elucidated structure. However, several minor deviations are present, notably the prediction of a slightly elongated Fe1$\mathrm{S} 1$ bond and a compressed Fe1-C11 bond by computation. In contrast to the geometric data in Table 1, the computed infrared data show large deviations from experiment (Table 2). Note, however, that this is a commonly observed phenomenon when frequencies are computed using the standard harmonic approximation. ${ }^{[27]}$ In order to partially overcome this systematic overestimation a scaling factor of 0.989 was applied, corresponding to the recommendation of Truhlar. ${ }^{[27]}$ Despite this inexpensive method that partially accounts for anharmonicity, ${ }^{[28]}$ computed frequencies remain too large. The differences, rather than the absolute quantitative values, however, are in excellent agreement with experimentally determined values, e.g. the difference between the two $\mathrm{CO}$ stretching frequencies for the five-coordinate complex is $63 \mathrm{~cm}^{-1}$ for experiment and $55 \mathrm{~cm}^{-1}$ for computation. Thus, it can be determined that our computational findings reproduce experiment quite satisfactorily.

Table 1. Comparison of bond lengths (in $\AA$ ) and bond angles (in degrees) for 1. Atom numbering follows Figure 2. Geometric optimization was carried out at the M06/pVDZ level.

\begin{tabular}{llll}
\hline & Exp. & $\begin{array}{l}\text { Gas phase } \\
\text { (comput.) }\end{array}$ & $\begin{array}{l}\text { THF-PCM } \\
\text { (comput.) }\end{array}$ \\
\hline Fe1-N1 & $2.002(3)$ & 2.004 & 2.000 \\
Fe1-S1 & $2.2163(12)$ & 2.227 & 2.239 \\
Fe1-C11 & $1.915(5)$ & 1.886 & 1.886 \\
Fe1-C1 & $1.773(5)$ & 1.785 & 1.780 \\
Fe1-C2 & $1.786(5)$ & 1.780 & 1.780 \\
C1-O1 & $1.155(5)$ & 1.143 & 1.145 \\
C2-O2 & $1.144(5)$ & 1.148 & 1.148 \\
C11-O7 & $1.209(5)$ & 1.200 & 1.205 \\
C11-Fe1-N1 & $85.26(17)$ & 85.65 & 85.57 \\
C1-Fe1-N1 & $177.08(17)$ & 175.13 & 175.29 \\
C2-Fe1-S1 & $162.50(18)$ & 162.49 & 164.22 \\
\hline
\end{tabular}

Table 2. Infrared data for wild-type enzyme, 1 (experiment), and $\mathbf{1}$ (computed).

\begin{tabular}{|c|c|}
\hline Complex & $v_{\mathrm{CO}}\left[\mathrm{cm}^{-1}\right]$ \\
\hline$[\mathrm{Fe}]$-hydrogenase ${ }^{[\mathrm{a}]}$ & 2011, 1944 \\
\hline 5-coordinate mimic (exp. $)^{[\mathrm{b}]}$ & 2022,1959 \\
\hline 5-coordinate mimic (comput.) ${ }^{[\mathrm{c}]}$ & 2140,2090 \\
\hline 5-coordinate mimic (comput. $)^{[\mathrm{d}]}$ & 2115,2060 \\
\hline CO-inhibited [Fe]-hydrogenase ${ }^{[a]}$ & 2074, 2020, 1981 \\
\hline CO-inhibited mimic (exp. $)^{[b]}$ & 2073, 2024, 1995 \\
\hline CO-inhibited mimic (comput.) ${ }^{[c]}$ & $2166,2126,2107$ \\
\hline CO-inhibited mimic (comput.) ${ }^{[\mathrm{d}]}$ & $2154,2106,2086$ \\
\hline
\end{tabular}

[a] Spectrum of sample dissolved in water. [b] Spectrum of sample dissolved in THF. [c] Spectrum of sample computed in the gas phase. [d] Spectrum of sample computed in THF implicit solvent.

\section{Ligand Binding}

Certain ligands are known to bind into the empty sixth coordination site of the wild-type [Fe]-hydrogenase enzyme, including $\mathrm{CO}$ and $\mathrm{CN}^{-}$, both of which inhibit enzymatic activity. ${ }^{[29]}$ Correspondingly, complex 1 was shown to react with $\mathrm{CO}$, forming a tris(carbonyl) complex. ${ }^{[5]}$ In addition, although a reaction with $\mathrm{PPh}_{3}$ was observed, the nature of the resulting product could not be definitively established. In contrast, attempts to produce a reaction with $\mathrm{H}_{2} \mathrm{O}$, $\mathrm{CH}_{3} \mathrm{CN}$, pyridine, $\mathrm{NEt}_{3}$, and $\mathrm{O}_{2}$ produced no detectable coordination into the empty sixth site.

To examine the origins of ligand binding in $\mathbf{1}$, we computed ligand-binding free energies of 1-ligand complexes with the thiolate ligand protonated and nonprotonated. ${ }^{[4 \mathrm{~d}]}$ Protonation of this sulfur-containing ligand is believed to be important during $\mathrm{H}_{2}$ heterolysis by the enzyme. ${ }^{[7,10 \mathrm{~b}]}$ The two different theoretical levels used (M06 and B3LYP$\mathrm{dDsC}$ ) provide reaction free energies based on two unique methodologies, the latter of which explicitly examines the role of dispersion interactions in forming six-coordinate $\mathrm{Fe}-$ ligand complexes. The ligands examined $-\mathrm{CH}_{3} \mathrm{CN}$, $\mathrm{CN}^{-}, \mathrm{CO}, \mathrm{H}^{-}, \mathrm{H}_{2}, \mathrm{H}_{2} \mathrm{O}, \mathrm{PMe}_{3}, \mathrm{PPh}_{3}$, pyridine, and THF were chosen to provide a variety of $\pi / \sigma$-acceptor/donor ability.

Examination of nonprotonated complex $\mathbf{1}$ confirms the original experimental findings: ${ }^{[5]}$ binding of $\mathrm{CO}$ to the fivecoordinate Fe complex is exergonic at all theoretical levels tested (Table 3, nonprotonated). In contrast, $\mathrm{PPh}_{3}$, which reacted to yield an unidentified product, is predicted to have an unfavourable binding free energy when the M06 functional is combined with the PCM solvation model, while a favourable binding energy is obtained using the B3LYP-dDsC/PCM functional and solvation model. When the more sophisticated COSMO-RS solvation model is used with the B3LYP-dDsC functional, the binding free energy is endergonic. These findings raise an important question: when different theoretical methods give opposing trends, how should results be interpreted? In this case, background knowledge on the different theoretical methods helps to explain the observations for $\mathrm{PPh}_{3}$. During a ligand-binding reaction two separate phenomena compete, each of which favours a different side of the reaction. Solvent interactions favour the separated reactants, which have greater surface contact with the solvent, while dispersion interactions become increasingly important for larger systems, such as the more bulky product complex (Figure 3). For our computations, B3LYP-dDsC provides a more accurate description of dispersion interactions, resulting in greater stabilization of the larger product complexes. The improved description of dispersion must also be accompanied by an enhanced treatment of solute/solvent interactions that favour the smaller reactant species over the larger products. ${ }^{[30]}$ This is achieved by using a more refined solvation model, COSMO-RS. Indeed, changing from the PCM to the COSMO-RS treatment of solvation causes a shift from exergonic to endergonic for the $\mathrm{PPh}_{3}$ ligand, as the description of the reactants is now improved. This trend holds for 
Table 3. Ligand-binding free energies (in $\mathrm{kcal} / \mathrm{mol}$ ) computed for the Fe complexes at $298 \mathrm{~K}$ in THF implicit solvent.

\begin{tabular}{lcccccc}
\hline \multirow{2}{*}{ Ligand } & \multicolumn{2}{c}{ Nonprotonated } & \multicolumn{3}{c}{ Protonated } \\
& M06/PCM & B3LYP-dDsC/PCM & B3LYP-dDsC/COSMO-RS & M06/PCM & B3LYP-dDsC/PCM & B3LYP-dDsC/COSMO-RS \\
\hline $\mathrm{CO}$ & -1.56 & -3.43 & -2.08 & -5.06 & -6.08 & -5.43 \\
$\mathrm{PPh}_{3}$ & 3.20 & -4.38 & 2.77 & -5.51 & -13.63 & -3.38 \\
$\mathrm{PMe}_{3}$ & -3.94 & -7.48 & -2.82 & -12.54 & -15.78 & -10.72 \\
$\mathrm{Pyridine}$ & 4.57 & -1.42 & 1.39 & -2.72 & -8.77 & -5.93 \\
$\mathrm{THF}$ & 10.71 & 3.35 & 6.68 & 2.41 & -4.75 & 0.81 \\
$\mathrm{H}_{2} \mathrm{O}$ & 7.85 & 3.71 & 8.52 & 2.60 & -1.33 & -1.63 \\
$\mathrm{CH}_{3} \mathrm{CN}$ & 8.98 & 5.85 & 5.97 & -1.62 & -5.33 & -2.24 \\
$\mathrm{CN}^{-}$ & -8.62 & -12.76 & -14.12 & -32.66 & -38.75 & -31.50 \\
$\mathrm{H}_{2}$ & 11.02 & 10.59 & 10.77 & 6.71 & 5.67 & 5.68 \\
$\mathrm{H}^{-}$ & -29.37 & -33.98 & $-63.15^{[\mathrm{a}]}$ & -56.63 & -63.24 & $-85.05^{[\mathrm{a}]}$ \\
\hline
\end{tabular}

[a] The solvation energies of the hydride anion predicted by COSMO-RS deviate significantly from other implicit solvation models (see Supporting Information for values at different theoretical levels and with different basis sets), while similar solvation energies are predicted for the cyanide anion.
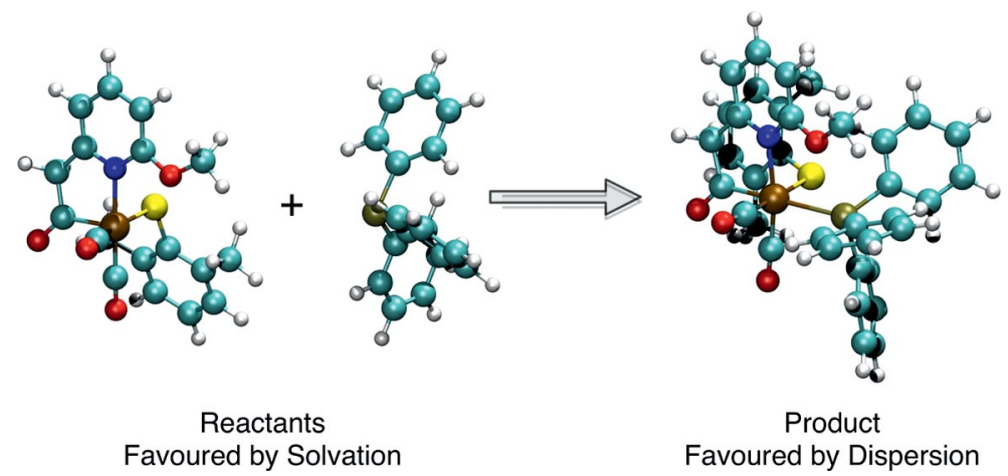

Figure 3. Reactants have more contact surface area with solvent and are favoured by solvation, while product complexes have more intramolecular dispersion interactions. The use of imbalanced dispersion-corrected density functionals (B3LYP-dDsC) with older solvation models (PCM) results in overstabilization of the product complex.

all ligands tested (with the exception of $\mathrm{H}_{2}$ ), as indicated in Table 3. Computations at the M06/PCM theoretical level also yield values similar to those from B3LYP-dDsC/ COSMO-RS, probably because the M06 function, which lacks an explicit description of dispersion interaction, and the PCM solvation model, which has less refined descriptions of hydrogen bonding and hydrophobic effects, more closely balance one another quantitatively. On the basis of our analysis, it is unlikely that a six-coordinate complex is formed with the $\mathrm{PPh}_{3}$ ligand under normal experimental conditions.

In contrast to the ligands discussed above, $\mathrm{H}_{2} \mathrm{O}$, THF, and $\mathrm{CH}_{3} \mathrm{CN}$ each have thermodynamically unfavourable reaction free energies (Table 3). To probe the role played by the transfer of electron density, the binding free energies of several additional ligands with varied $\pi$-accepting/donating ability were tested. The results reveal interesting patterns. The binding free energies in Table 3 show that favourable binding is loosely associated with the $\pi$-accepting ability of the ligand in question. For instance, $\mathrm{CO}$ and $\mathrm{CN}^{-}$are amongst the strongest $\pi$ acceptors, and each has exergonic binding free energies. Ligands with intermediate $\pi$-ac- fcepting ability, including the phosphanes and pyridine, tend toward thermoneutrality. On the other hand, $\pi$-donating ligands have endergonic free energies, as exemplified by $\mathrm{H}_{2} \mathrm{O}$.

Protonation of the thiolate ligand of the Fe complex has been proposed as an important intermediate step in the catalytic heterolysis of $\mathrm{H}_{2} \cdot{ }^{[7,10 \mathrm{~b}]}$ Since understanding ligand binding in biomimics may shed light upon the chemistry associated with the relevant catalytic cycles, we examined binding free energies of the same set of ligands with $1+\mathrm{H}^{+}$ (where the thiolate ligand in $\mathbf{1}$ is protonated). As indicated in Table 3 (protonated), protonation shifts the reaction free energies significantly toward exergonicity as a result of increased $\sigma$ bonding between the $\mathrm{Fe}$ complex and the ligand (see above). Not only will strong $\pi$ acceptors $\left(\mathrm{CO}\right.$ and $\left.\mathrm{CN}^{-}\right)$ and phosphane compounds bind, but also weaker $\pi$ acceptors, such as pyridine and acetonitrile. Anionic species have particularly favourable binding free energies, owing to attraction between the positively charged iron complex and the anionic ligands. Note that our finding for the ability of $\mathrm{H}_{2} \mathrm{O}$ to bind to complex $\mathbf{1}+\mathrm{H}^{+}$parallels the "ligandswapped" results of Reiher discussed earlier. ${ }^{[1]}$ Although 
Table 4. Charge transfer analysis (ALMO-CTA) of ligand binding. Charge transfer computations at the M06/def2-SVP level, gas-phase electronic binding energy computations at the B3LYP-dDsC/TZP//M06/pVDZ level (in $\mathrm{kcal} / \mathrm{mol}$ ).

\begin{tabular}{|c|c|c|c|c|c|c|}
\hline Ligand & $\mathrm{Fe} \rightarrow$ ligand donation & $\begin{array}{l}\text { Neutral } \\
\text { Ligand } \rightarrow \text { Fe donation }\end{array}$ & Binding energy & $\mathrm{Fe} \rightarrow$ ligand donation & $\begin{array}{l}\text { Protonated } \\
\text { Ligand } \rightarrow \mathrm{Fe} \text { donation }\end{array}$ & Binding energy \\
\hline $\mathrm{CO}$ & 24.90 & 13.30 & -15.17 & 22.40 & 13.00 & -20.09 \\
\hline $\mathrm{PPh}_{3}$ & 6.64 & 13.75 & -18.39 & 4.31 & 15.70 & -34.37 \\
\hline $\mathrm{PMe}_{3}$ & 6.57 & 17.84 & -20.68 & 4.87 & 19.35 & -32.22 \\
\hline Pyridine & 2.67 & 8.95 & -13.21 & 1.56 & 10.99 & -24.98 \\
\hline $\mathrm{THF}$ & 0.48 & 4.91 & -8.62 & 0.13 & 7.00 & -20.67 \\
\hline $\mathrm{H}_{2} \mathrm{O}$ & 4.01 & 8.48 & -9.62 & 2.25 & 7.63 & -14.73 \\
\hline $\mathrm{CH}_{3} \mathrm{CN}$ & 5.61 & 8.78 & -5.29 & 4.43 & 9.66 & -19.65 \\
\hline $\mathrm{CN}^{-}$ & 3.82 & 18.88 & -48.49 & 3.57 & 18.73 & -132.84 \\
\hline $\mathrm{H}_{2}$ & 5.00 & 11.25 & 1.37 & 4.51 & 11.90 & -5.64 \\
\hline $\mathrm{H}^{-}$ & -0.60 & 27.52 & -71.00 & 0.65 & 27.00 & -161.31 \\
\hline
\end{tabular}

small quantitative changes are seen, the binding ability of $\mathrm{H}_{2} \mathrm{O}$ is retained in each model: the wild-type enzyme active site, an artificial active site possessing coordination features of [FeFe]-hydrogenase (as opposed to [Fe]-hydrogenase), and the $[\mathrm{Fe}]-$ hydrogenase mimic $\mathbf{1}+\mathrm{H}^{+}$. These results further confirm that certain changes to the first coordination shell of the active site do not result in dramatic changes in the ability to bind small molecules.

To gain deeper insight into the roles played by the donation/reception of electron density in ligand binding, absolutely localized molecular orbitals - charge transfer analysis $^{[24-25]}$ (ALMO-CTA, also known as BLW-EDA) computations were undertaken. ALMO-CTA allows for dissection of the charge transfer occurring between a ligand of interest and the $\mathrm{Fe}$ centre, represented in terms of $\mathrm{Fe} \rightarrow$ ligand and ligand $\rightarrow \mathrm{Fe}$ donation. The results listed in Table 4 reveal several interesting trends. For instance, CO, which has a favourable binding free energy, benefits from a much larger stabilization arising from $\mathrm{Fe} \rightarrow$ ligand donation than any of the other ligands. In fact, the amount of donation yields no discernible pattern regarding the endergonicity/exergonicity of the overall gas-phase binding energies. For example, the stabilization from donation from the $\mathrm{Fe}$ centre to an acetonitrile ligand $(5.61 \mathrm{kcal} / \mathrm{mol})$ is larger than the corresponding donation to a pyridine ligand $(2.67 \mathrm{kcal} /$ mol), yet the latter has a more exergonic binding free energy $(-5.29$ vs. $-13.21 \mathrm{kcal} / \mathrm{mol})$. Thus, the donation of electron density from metal to ligand appears to have no significant effect on the overall reaction binding energy.

On the other hand, ligand $\rightarrow \mathrm{Fe}$ donation does reveal a trend that directly correlates with the gas-phase binding free energies: ligands that show strong donating ability have more exergonic binding free energies than weaker donors. Indeed, the five ligands with the highest stabilization from donation $\left(\mathrm{CN}^{-}, \mathrm{PMe}_{3}, \mathrm{PPh}_{3}, \mathrm{CO}\right.$, pyridine) each exhibit strongly exergonic gas-phase binding energies (Table 4). Moreover, examination of the protonated thiolate ligand model shows increased stability from ligand $\rightarrow \mathrm{Fe}$ donation and a small decrease from $\mathrm{Fe} \rightarrow$ ligand donation. Evidently, the electronic nature of the central $\mathrm{Fe}$ atom is sufficiently altered by the presence of a protonated thiolate ligand to increase its ability to accept $\sigma$ electrons. In general, each ligand's ability to donate electron density is probably the determining factor in its overall binding ability with the $\mathrm{Fe}$ centre in the gas phase.

The binding of both $\mathrm{H}_{2}$ and $\mathrm{H}^{-}$is highly relevant in the cycle that catalyses the reaction given in Scheme 1. One key requirement for the reaction to proceed is a weakly endergonic or exergonic binding free energy of $\mathrm{H}_{2}$ to the fivecoordinate Fe complex, which is the essential first step for catalysis. After $\mathrm{H}_{2}$ heterolysis, the hydride product must be removed to regenerate the original starting product. Our computations (Table 3 ) indicate, however, that the binding energy of $\mathrm{H}_{2}$ is quite unfavourable and the removal of $\mathrm{H}^{-}$ is also difficult (although likely not to the degree predicted by COSMO-RS; see Supporting Information). While removal of the hydride ion is assisted in vivo by the $\mathrm{MPT}^{+}$ substrate, the nonbinding of $\mathrm{H}_{2}$ represents a significant challenge for the construction of functional biomimics and raises questions as to whether the $\mathrm{H}_{2}$ molecule is directly bonded to the Fe ion or is simply held in place by the protein in the native enzyme.

\section{Conclusions}

With the objective of understanding the stereoelectronic effects that dictate ligand binding in [Fe]-hydrogenase biomimics, we computed binding free energies for a series of ligands with a recently synthesized [Fe]-hydrogenase biomimic (complex 1). Anionic ligands (e.g. $\mathrm{CN}^{-}$) have highly exergonic binding free energies with both the neutral and protonated states of the Fe biomimic, while strong $\sigma$ donors (e.g. CO) also bind favourably. As a ligand's donating ability decreases, binding free energies drop from nearly thermoneutral for intermediate donors (e.g. pyridine), to endergonic for poor donors, such as acetonitrile. An analysis of the degree of charge transfer between the Fe complex and a ligand confirms a correlation between donating ability of the ligand and binding affinity.

Supporting Information (see footnote on the first page of this article): Electronic and free energies and Cartesian coordinates of relevant structures are provided. 


\section{Acknowledgments}

Prof. Clémence Corminboeuf (EPFL) is acknowledged for insightful suggestions and comments. The Laboratory of Computational Molecular Design at EPFL is acknowledged for providing computational resources. This work is supported by the Swiss National Science Foundation (project number 200020_134473/1).

[1] a) E. J. Lyon, S. Shima, R. Boecher, R. K. Thauer, F. W. Grevels, E. Bill, W. Roseboom, S. P. J. Albracht, J. Am. Chem. Soc. 2004, 126, 14239; b) S. Shima, E. J. Lyon, M. S. Sordel-Klippert, M. Kauss, J. Kahnt, R. K. Thauer, K. Steinbach, X. L. Xie, L. Verdier, C. Griesinger, Angew. Chem. 2004, 116, 2601; Angew. Chem. Int. Ed. 2004, 43, 2547.

[2] R. K. Thauer, A. R. Klein, G. C. Hartmann, Chem. Rev. 1996, 96, 3031 .

[3] a) S. Shima, E. J. Lyon, R. K. Thauer, B. Mienert, E. Bill, J. Am. Chem. Soc. 2005, 127, 10430; b) M. Korbas, S. Vogt, W. Meyer-Klaucke, E. Bill, E. J. Lyon, R. K. Thauer, S. Shima, J. Biol. Chem. 2006, 281, 30804; c) S. Shima, O. Pilak, S. Vogt, M. Schick, M. S. Stagni, W. Meyer-Klaucke, E. Warkentin, R. K. Thauer, U. Ermler, Science 2008, 321, 572; d) T. Hiromoto, K. Ataka, O. Pilak, S. Vogt, M. S. Stagni, W. Meyer-Klaucke, E. Warkentin, R. K. Thauer, S. Shima, U. Ermler, FEBS Lett. 2009, 583, 585; e) T. Hiromoto, E. Warkentin, J. Moll, U. Ermler, S. Shima, Angew. Chem. 2009, 121, 6579; Angew. Chem. Int. Ed. 2009, 48, 6457-6460; f) M. Salomone-Stagni, F. Stellato, C. M. Whaley, S. Vogt, S. Morante, S. Shima, T. B. Rauchfuss, W. Meyer-Klaucke, Dalton Trans. 2010, 39, 3057; g) S. Shima, S. Vogt, A. Gobels, E. Bill, Angew. Chem. 2010, 122, 10113; Angew. Chem. Int. Ed. 2010, 49, 9917; h) J. A. Wright, P. J. Turrell, C. J. Pickett, Organometallics 2010, 29, 6146-6156.

[4] a) X. F. Wang, Z. M. Li, X. R. Zeng, Q. Y. Luo, D. J. Evans, C. J. Pickett, X. M. Liu, Chem. Commun. 2008, 3555; b) P. J. Turrell, J. A. Wright, J. N. T. Peck, V. S. Oganesyan, C. J. Pickett, Angew. Chem. 2010, 122, 7670; Angew. Chem. Int. Ed. 2010, 49, 7508; c) B. Li, T. Liu, C. V. Popescu, A. Bilko, M. Y. Darensbourg, Inorg. Chem. 2009, 48, 11283; d) A. M. Royer, T. B. Rauchfuss, D. L. Gray, Organometallics 2009, 28, 3618; e) A. M. Royer, M. Salomone-Stagni, T. B. Rauchfuss, W. MeyerKlaucke, J. Am. Chem. Soc. 2010, 132, 16997; f) S. Tanino, Y. Ohki, K. Tatsumi, Chem. Asian J. 2010, 5, 1962; g) T. B. Liu, B. Li, C. V. Popescu, A. Bilko, L. M. Pérez, M. B. Hall, M. Y. Darensbourg, Chem. Eur. J. 2010, 16, 3083; h) B. V. Obrist, D. F. Chen, A. Ahrens, V. Schunemann, R. Scopelliti, X. L. Hu, Inorg. Chem. 2009, 48, 3514; i) D. F. Chen, R. Scopelliti, X. L. Hu, J. Am. Chem. Soc. 2010, 132, 928; j) D. F. Chen, R. Scopelliti, X. L. Hu, Angew. Chem. 2010, 122, 7674; Angew. Chem. Int. Ed. 2010, 49, 7512; k) D. F. Chen, A. Ahrens-Botzong, V. Schunemann, R. Scopelliti, X. L. Hu, Inorg. Chem. 2011, 50, 5249; 1) D. F. Chen, R. Scopelliti, X. L. Hu, Angew. Chem. 2012, 124, 1955; Angew. Chem. Int. Ed. 2012, 51, 19191921; m) B. Hu, D. F. Chen, X. L. Hu, Chem. Eur. J. 2012, 18, 11528-11530.

[5] D. F. Chen, R. Scopelliti, X. L. Hu, Angew. Chem. 2011, 123, 5789; Angew. Chem. Int. Ed. 2011, 50, 5671-5673.

[6] N. Nakatani, Y. Nakao, H. Sato, S. Sakaki, Chem. Lett. 2009, 38, 958-959.

[7] A. Dey, J. Am. Chem. Soc. 2010, 132, 13892-13901.

[8] L. Yu, C. Greco, M. Bruschi, U. Ryde, L. De Gioia, M. Reiher, Inorg. Chem. 2011, 50, 3888-3900.

[9] a) J. W. Tye, M. Y. Darensbourg, M. B. Hall, J. Comput. Chem. 2006, 27, 1454-1462; b) J. W. Tye, M. Y. Darensbourg, M. B. Hall, Inorg. Chem. 2008, 47, 2380-2388.

[10] a) X. Yang, M. B. Hall, J. Am. Chem. Soc. 2008, 130, 1403614037; b) X. Yang, M. B. Hall, J. Am. Chem. Soc. 2009, 131, 10901-10908.
[11] a) M. T. Stiebritz, M. Reiher, Inorg. Chem. 2010, 49, 58185823; b) M. T. Stiebritz, A. R. Finkelmann, M. Reiher, Eur. J. Inorg. Chem. 2011, 1163-1171.

[12] a) Y. Zhao, D. G. Truhlar, Theor. Chem. Acc. 2008, 120, 215241; b) Y. Zhao, D. G. Truhlar, Acc. Chem. Res. 2008, 41, 157167.

[13] A. Schafer, H. Horn, R. Ahlrichs, J. Chem. Phys. 1992, 97, 2571-2577.

[14] M. J. Frisch, G. W. Trucks, H. B. Schlegel, G. E. Scuseria, M. A. Robb, J. R. Cheeseman, G. Scalmani, V. Barone, B. Mennucci, G. A. Petersson, H. Nakatsuji, M. Caricato, X. Li, H. P. Hratchian, A. F. Izmaylov, J. Bloino, G. Zheng, J. L. Sonnenberg, M. Hada, M. Ehara, K. Toyota, R. Fukuda, J. Hasegawa, M. Ishida, T. Nakajima, Y. Honda, O. Kitao, H. Nakai, T. Vreven, J. A. Montgomery Jr, J. E. Peralta, F. Ogliaro, M. Bearpark, J. J. Heyd, E. Brothers, K. N. Kudin, V. N. Staroverov, R. Kobayashi, J. Normand, K. Raghavachari, A. Rendell, J. C. Burant, S. S. Iyengar, J. Tomasi, M. Cossi, N. Rega, M. J. Millam, M. Klene, J. E. Knox, J. B. Cross, V. Bakken, C. Adamo, J. Jaramillo, R. Gomperts, R. E. Stratmann, O. Yazyev, A. J. Austin, R. Cammi, C. Pomelli, J. W. Ochterski, R. L. Martin, K. Morokuma, V. G. Zakrzewski, G. A. Voth, P. Salvador, J. J. Dannenberg, S. Dapprich, A. D. Daniels, O. Farkas, J. B. Foresman, J. V. Ortiz, J. Cioslowski, D. J. Fox, Gaussian 09, rev. B.01, Gaussian, Inc., Wallingford, CT, 2009.

[15] a) A. D. Becke, J. Chem. Phys. 1993, 98, 5648-5652; b) C. Lee, W. Yang, R. G. Parr, Phys. Rev. B 1988, 37, 785-789.

[16] a) S. N. Steinmann, C. Corminboeuf, J. Chem. Theory Comput. 2011, 7, 3567-3577; b) S. N. Steinmann, C. Corminboeuf, $J$. Chem. Phys. 2011, 134, 044117; c) S. N. Steinmann, C. Corminboeuf, Chimia 2011, 65, 240-244; d) S. N. Steinmann, C. Corminboeuf, J. Chem. Theory Comput. 2010, 6, 1990-2001.

[17] a) G. te Velde, F. M. Bickelhaupt, S. J. A. van Gisbergen, C. Fonseca Guerra, E. J. Baerends, J. G. Snijders, T. Ziegler, J. Comput. Chem. 2001, 22, 931-967; b) C. Fonseca Guerra, J. G. Snijders, G. te Velde, E. J. Baerends, Theor. Chem. Acc. 1998, 99, 391-403.

[18] ADF2012, SCM, Theoretical Chemistry, Vrije Universiteit, Amsterdam, The Netherlands, http://www.scm.com.

[19] a) A. J. Olaya, P. Ge, J. F. Gonthier, P. Pechy, C. Corminboeuf, H. H. Girault, J. Am. Chem. Soc. 2011, 133, 12115-12123; b) S. Rochat, S. N. Steinmann, C. Corminboeuf, K. Severin, Chem. Commun. 2011, 47, 10584-10586.

[20] S. N. Steinmann, C. Piemontesi, A. Delachat, C. Corminboeuf, J. Chem. Theory Comput. 2012, 8, 1629-1640.

[21] P. Ge, T. K. Todorova, I. Hatay Patir, A. J. Olaya, H. Vrubel, M. Mendez, X. L. Hu, C. Corminboeuf, H. H. Girault, Proc. Natl. Acad. Sci. USA 2012, 109, 11558-11563.

[22] J. Tomasi, B. Mennucci, R. Cammi, Chem. Rev. 2005, 105, 2999-3093.

[23] A. Klamt, WIREs Comp. Mol. Sci. 2011, 1, 699-709.

[24] a) Y. Mo, S. D. Peyerimhoff, J. Chem. Phys. 1998, 109, 16871697; b) Y. Mo, J. L. Gao, S. D. Peyerimhoff, J. Chem. Phys. 2000, 112, 5530-5531.

[25] R. Z. Khaliullin, A. T. Bell, M. Head-Gordon, J. Chem. Phys. 2008, 128, 184112.

[26] Y. Shao, L. Fusti-Molnar, Y. Jung, J. Kussmann, C. Ochsenfeld, S. T. Brown, A. T. B. Gilbert, L. V. Slipchenko, S. V. Levchenko, D. P. O’Neill, R. A. Distasio Jr., R. C. Lochan, T. Wang, G. J. O. Beran, N. A. Besley, J. M. Herbert, C. Y. Lin, T. Van Voorhis, S. H. Chien, A. Sodt, R. P. Steele, V. A. Rassolov, P. E. Maslen, P. P. Korambath, R. D. Adamson, B. Austin, J. Baker, E. F. C. Byrd, H. Dachsel, R. J. Doerksen, A. Dreuw, B. D. Dunietz, A. D. Dutoi, T. R. Furlani, S. R. Gwaltney, A. Heyden, S. Hirata, C.-P. Hsu, G. Kedziora, R. Z. Khalliulin, P. Klunzinger, A. M. Lee, M. S. Lee, W. Liang, I. Lotan, N. Nair, B. Peters, E. I. Proynov, P. A. Pieniazek, Y. M. Rhee, J. Ritchie, E. Rosta, C. D. Sherrill, A. C. Simmonett, J. E. Subotnik, H. L. Woodcock III, W. Zhang, A. T. Bell, A. K. Chakraborty, D. M. Chipman, F. J. Keil, A. Warshel, W. J. Hehre, H. F. 
Schaefer III, J. Kong, A. I. Krylov, P. M. W. Gill, M. HeadGordon, Phys. Chem. Chem. Phys. 2006, 8, 3172-3191.

[27] I. M. Alecu, J. Zheng, Y. Zhao, D. G. Truhlar, J. Chem. Theory Comput. 2010, 6, 2872-2887.

[28] A. P. Scott, L. Radom, J. Phys. Chem. 1996, 100, 16502-16513.

[29] E. J. Lyon, S. Shima, G. Buurman, S. Chowdhuri, A. Batschauer, K. Steinbach, R. K. Thauer, Eur. J. Biochem. 2004, 271, 195-204.
[30] a) U. Ryde, R. A. Mata, S. Grimme, Dalton Trans. 2011, 40, 11176-11183; b) H. Jacobsen, L. Cavallo, ChemPhysChem 2012, 13, 562-569; c) S. Grimme, ChemPhysChem 2012, 13, $1407-1409$.

Received: January 21, 2013

Published Online: April 16, 2013 